\title{
Cross-sectional study of perceptions of qualities of a good medical teacher among medical students from first to final year
}

Matthew Jian Wen Low ${ }^{1}$, MBBS, MRCEM, Kathleen Swee Min ${\underline{K h o 0^{1}}}^{1}$ MBBS, MRCEM, Win Sen $\underline{K u a n}^{1,2}$, MBBS, MRCS, Shirley Beng Suat $\underline{\mathrm{Ooi}}^{1,2}$, MBBS, FRCS

\begin{abstract}
INTRODUCTION Defining the characteristics of a good medical teacher has implications for faculty selection and development. Perceptions of characteristics may differ with cultural context and level of training, as medical students progress from didactic preclinical training based on cognitivist learning theory to more complex integration of theory and practice in specific contexts in clinical training based on constructivist learning theory.

METHODS We modified a validated questionnaire with permission from the original authors at Melaka Manipal Medical College, Melaka, Malaysia. Participants rated 35 characteristics on a 5-point Likert scale. The modified questionnaire was validated in a pilot pool of medical students $(n=69)$, with a Cronbach's alpha of 0.90 , and administered to Year $1-5$ medical students $(n=917)$ at the Yong Loo Lin School of Medicine, National University of Singapore, Singapore.

RESULTS Based on the proportion of favourable Likert scoring, four top desirable characteristics were common across Year 1-5 students: good communication skills (84.4\%); sound knowledge of subject (82.7\%); enthusiasm (78.4\%); and providing effective explanations $(74.4 \%)$. Approachability $(p=0.005)$, encouraging participation $(p<0.001)$ and constructive criticism $(p<0.001)$ were more important to clinical students (Year $3-5)$ than preclinical students (Year 1-2). CONCLUSION The top four characteristics were consistent across all years of medical students in this study. Characteristics emphasised in the clinical years facilitate active learner participation, consistent with constructivist learning theory.
\end{abstract}

Keywords: learner perspectives, medical education, undergraduate

\section{INTRODUCTION}

Harden and Crosby ${ }^{(1)}$ proposed that a good teacher has a larger effect on improving student achievement than other factors, such as class size. Although good medical teachers are important, there are differing perspectives in the literature regarding their definition, with more opinions than empirical data. Elucidating specific characteristics of good medical teachers would clarify this definition.

Sutkin et $\mathrm{al}^{(2)}$ conducted a systematic review of 68 articles in the literature and grouped the descriptors into 49 themes, which in turn were clustered into three major categories of teacher, physician and human characteristics. Teacher characteristics included generic teaching skills as well as knowledge and application of teaching methods. Physician characteristics included clinical knowledge, clinical skills and experience. Human characteristics included relationship skills, emotional states and personality types. The authors found that human characteristics were predominant over teacher and physician characteristics. This systematic review, although comprehensive, addressed medical teaching generically rather than specific stages of training.

Cultural differences in an Asian context may lead to a different emphasis ${ }^{(3)}$ from Western contexts. ${ }^{(4)}$ Due to the relative paucity of Asian literature on this matter, it is unclear whether differences in emphasis are consistent across different Asian countries. Kikukawa et al ${ }^{(5)}$ conducted focus group interviews with resident physicians in Japan and found an emphasis on teacher characteristics instead, such as providing feedback or presenting residents with opportunities to think. Singh et $\mathrm{al}^{(6)}$ devised and validated a questionnaire (Cronbach's alpha 0.86) based on the characteristics of a good medical teacher derived from current literature and administered it to faculty members of a medical and dental undergraduate course in Melaka, Malaysia. They found that knowledge of a subject, enthusiasm and communication skills were the top three desirable characteristics, emphasising human and physician characteristics.

It is important to consider the differences at varying stages of medical training, as appropriate teaching approaches may differ with increasing learner maturity and skill. ${ }^{(7)}$ Ertmer and Newby ${ }^{(8)}$ suggest that increasing cognitive demands and increasing levels of learner knowledge, such as the progression seen in medical training, are best served by moving from behavioural and cognitivist strategies initially to constructivist strategies at later stages of training. Desirable teacher characteristics may change in tandem with teaching strategies as learners progress. ${ }^{(9)}$

Kua et $\mathrm{al}^{(10)}$ sought to determine whether there were differences in desired medical teacher characteristics for first-year medical students compared to final-year medical students. They surveyed first- and final-year Singapore medical students using a narrower scope of characteristics derived from author judgement, and

${ }^{1}$ Emergency Medicine Department, National University Hospital, National University Health System, ${ }^{2}$ Department of Surgery, Yong Loo Lin School of Medicine, National University of Singapore, Singapore

Correspondence: Dr Matthew Low, Senior Resident, Emergency Medicine Department, National University Hospital, 5 Lower Kent Ridge Road, Singapore 119074. matthew_low@nuhs.edu.sg 
found variation in desired characteristics, with first-year students preferring handouts while final-year students emphasised encouraging student participation and empathy. The ability to motivate students and being passionate about teaching were the most desirable across first- and final-year students, which can retrospectively be recognised as a balance between teacher (motivating students) and human (passionate about teaching) characteristics.

We hypothesised that the balance between teacher and human characteristics would change as learners progress through their training, in a manner consistent with progression from behavioural and cognitivist learning strategies to constructivist strategies in the later years, and that this emphasis would vary across different Asian countries. We also hypothesised that considering a wider scope of characteristics, derived from the most current literature, would lead to different results from the existing Singapore literature.

We conducted our study at the Yong Loo Lin School of Medicine, National University of Singapore (NUS Medicine), Singapore. Singapore has an interesting mix of cultural influences. It is an English-speaking Southeast Asian former British colony with a majority ethnic Chinese population, significant ethnic minority populations (Malay $13.4 \%$, Indian $9.1 \%$, other $3.2 \%$ ), ${ }^{(11)}$ and firstworld living standards. It represented a mix of Asian and Western perspectives for the purposes of this study. NUS Medicine is a leading Asian medical school ${ }^{(12)}$ that trains a majority of doctors practising in Singapore.

\section{METHODS}

This cross-sectional study was conducted from May to November 2015. Participants comprised first-year to final-year medical students of the five-year undergraduate medicine course. Ethical approval was obtained from the NUS Institutional Review Board (reference no. 2014/01203). Informed consent was obtained from all participants of the study.

We adapted a validated questionnaire by Singh et $\mathrm{al}^{(6)}$ with kind permission from the original authors. Additional characteristics derived from the systematic review by Sutkin et $\mathrm{al}^{(2)}$ were included in the questionnaire based on our judgement of which characteristics were most likely to be important (Appendix). The questionnaire was initially disseminated to selected faculty members at NUS Medicine and the Centre for Medical Education at NUS for review and refinement, and to residents at National University Hospital, Singapore, for cognitive interviewing to ensure accuracy of questionnaire interpretation.

The adapted questionnaire was validated using a pilot pool of 69 first-year medical students that was separate from the eventual survey participants. With the exclusion of two out of 37 characteristics from the questionnaire, namely 'inflexible regarding maintaining classroom discipline' and 'very generous in assessing the performance of students during exams', we derived a Cronbach's alpha of 0.90 , indicating good internal consistency. The aforementioned two characteristics were excluded from further analysis.
There were 35 statements relating to the characteristics of effective teachers in our questionnaire. The questionnaire was administered in a paper format to medical students at NUS Medicine between May and November 2015. Participants were asked to score these on a 5-point Likert scale (strongly agree $=5$ to strongly disagree $=1$ ). Participants could also suggest three other characteristics and rank these on the same Likert scale. At the end of the questionnaire, participants were asked to choose their top five most important characteristics, in anticipation of multiple characteristics receiving the maximum rating on the Likert scale.

Data was tabulated using Microsoft Excel 2013 (Microsoft Inc, Redmond, WA, USA) and analysed using STATA 14 (StataCorp LP, College Station, TX, USA). Responses to items using the Likert scale were reported using median and proportion of students who responded positively. Characteristics of individual items were analysed for differences among the various years of study using the Kruskal-Wallis test and for trends using chi-square test. Characteristics were grouped according to teacher, physician and human characteristics according to Sutkin's meta-analysis. ${ }^{(2)}$

\section{RESULTS}

We received responses from students of all years with varying response rates: Year 1 (77.0\%, 231/300 students); Year 2 (56.7\%, 170/300 students); Year 3 (46.0\%, 139/302 students); Year 4 (82.4\%, 248/301 students); and Year 5 (45.6\%, 129/283 students). Year 1-2 students were grouped as preclinical students, while Year 3-5 students were grouped as clinical students.

Based on an aggregate of Likert scale scoring, human $(56.8 \%)$ and teacher $(53.4 \%)$ characteristics were generally rated more favourably by all students when compared to physician characteristics (36.3\%). Based on the proportion of favourable Likert scale scoring, four top characteristics were common across all five years of study: 'has good communication skills' (84.4\% of all respondents); 'has a sound knowledge of the subject' (82.7\%); 'enthusiastic and has passion to teach' (78.4\%); and 'provides effective explanations, answers and demonstrations' (74.4\%). The fifth most important characteristic was 'being patient with others' for Year 1-4 students and 'offers constructive criticism to students' for Year 5 students (Table I).

The following were most commonly selected as the top most important characteristic at the end of the questionnaire (Table II): 'has good communication skills' for preclinical students (19.9\% of responses in Year 1; $14.7 \%$ in Year 2); 'enthusiastic and has passion to teach' for Year 4 students (13.7\% of responses); and 'provides effective explanations, answers and demonstrations' for Year 3 and Year 5 students (14.4\% of responses in Year 3; $17.1 \%$ in Year 5), showing a significant overlap with the top characteristics derived from Likert scale scoring.

Analysis for trend found a significant tendency towards emphasis of the following characteristics in the clinical years when compared to the preclinical years: 'aware of students' interests and needs' ( $p=0.001)$; 'is easily approachable/affable' $(p=0.005)$; 'encourages student participation during theory lecture classes' $(p<0.001)$; 'offers constructive criticism to 
Table I. Percentage of participants who scored 5 on the Likert scale (or 1 if inversely phrased).

\begin{tabular}{|c|c|c|c|c|c|c|c|c|c|}
\hline \multirow[t]{3}{*}{ Domain } & \multirow[t]{3}{*}{ Question } & \multicolumn{6}{|c|}{$\%$} & \multicolumn{2}{|c|}{ p-value } \\
\hline & & \multirow{2}{*}{$\begin{array}{l}\text { All } \\
(n=917)\end{array}$} & \multicolumn{3}{|c|}{ Preclinical students } & \multicolumn{2}{|c|}{ Clinical students } & \multirow{2}{*}{$\begin{array}{l}\text { Kruskal-Wallis } \\
\text { test }\end{array}$} & \multirow{2}{*}{$\begin{array}{l}\text { Chi-square } \\
\text { test }\end{array}$} \\
\hline & & & $\begin{array}{l}\text { Yr } 1 \\
(n=231)\end{array}$ & $\begin{array}{l}\text { Yr } 2 \\
(\mathrm{n}=170)\end{array}$ & $\begin{array}{l}\text { Yr } 3 \\
(n=139)\end{array}$ & $\begin{array}{l}\text { Yr } 4 \\
(n=248)\end{array}$ & $\begin{array}{l}\text { Yr } 5 \\
(n=129)\end{array}$ & & \\
\hline Human & $\begin{array}{l}\text { Has good communication skills - conveys ideas and concerns clearly to } \\
\text { patients, relatives, colleagues and students, listens well }\end{array}$ & 84.4 & 85.3 & 82.9 & 87.1 & 83.1 & 84.5 & 0.821 & 0.784 \\
\hline Human & Impatient with others (inversely phrased) & 75.2 & 74.9 & 78.2 & 79.1 & 75.8 & 66.7 & 0.083 & 0.212 \\
\hline Human & Is easily approachable/affable & 67.5 & 64.1 & 59.4 & 69.1 & 73.8 & 70.5 & $0.015^{*}$ & $0.005^{*}$ \\
\hline Human & Acts as a role model, sets an example & 66.4 & 66.7 & 61.2 & 71.2 & 66.9 & 66.7 & 0.325 & 0.420 \\
\hline Human & Honest, moral and ethical & 62.1 & 64.5 & 65.3 & 68.3 & 56.9 & 56.6 & 0.083 & $0.042^{*}$ \\
\hline Human & Willing to learn and open to change (flexible) & 44.4 & 46.8 & 44.7 & 45.3 & 39.9 & 47.3 & 0.873 & 0.757 \\
\hline Human & Appreciates culture and different cultural backgrounds & 40.2 & 43.7 & 40.6 & 43.2 & 34.7 & 41.1 & 0.202 & 0.325 \\
\hline Human & Punctual & 39.3 & 44.6 & 47.1 & 36.0 & 32.3 & 36.4 & $0.006^{*}$ & $0.002^{*}$ \\
\hline Human & Uses a good sense of humour in teaching sessions & 31.5 & 26.8 & 30.6 & 37.4 & 32.3 & 33.3 & 0.082 & 0.236 \\
\hline Teacher & Enthusiastic and has passion to teach, enjoys teaching & 78.4 & 74.5 & 81.8 & 84.2 & 75.4 & 80.6 & 0.075 & 0.406 \\
\hline Teacher & $\begin{array}{l}\text { Provides effective explanations, answers and demonstrations - easily } \\
\text { remembered, crystallises concepts accurately and succinctly }\end{array}$ & 74.4 & 72.7 & 72.4 & 75.5 & 76.2 & 75.2 & 0.649 & 0.217 \\
\hline Teacher & Unbiased - such as in assessment of and interaction with students & 64.9 & 69.3 & 70.6 & 64.7 & 60.9 & 57.4 & 0.081 & $0.006^{*}$ \\
\hline Teacher & Inspiring and motivational to students & 64.2 & 61.5 & 61.2 & 70.5 & 64.5 & 65.9 & 0.175 & 0.148 \\
\hline Teacher & Stimulates trainees' thinking & 63.4 & 63.2 & 59.4 & 67.6 & 62.5 & 65.9 & 0.511 & 0.402 \\
\hline Teacher & Trusts and respects students & 62.3 & 61.0 & 59.4 & 66.2 & 61.3 & 65.9 & 0.755 & 0.329 \\
\hline Teacher & Has good presentation skills - memorable, a pleasure to listen to or to watch & 62.2 & 62.8 & 64.7 & 69.1 & 58.5 & 57.4 & 0.205 & 0.212 \\
\hline Teacher & $\begin{array}{l}\text { Encourages trainees' active involvement in clinical work, e.g. patient care, } \\
\text { patient procedures }\end{array}$ & 61.9 & 61.9 & 55.3 & 64.0 & 66.9 & 58.9 & $0.049^{*}$ & 0.209 \\
\hline Teacher & Caring and shows empathy towards students & 61.7 & 61.5 & 56.5 & 61.2 & 64.1 & 65.1 & 0.469 & 0.139 \\
\hline Teacher & Aware of students' interests and needs & 61.2 & 55.8 & 54.1 & 67.6 & 63.7 & 68.2 & $0.008^{*}$ & $0.001^{*}$ \\
\hline Teacher & Offers constructive criticism to students & 58.3 & 50.6 & 48.8 & 68.3 & 59.7 & 71.3 & $<0.001^{*}$ & $<0.001^{*}$ \\
\hline Teacher & $\begin{array}{l}\text { Emphasises observational skills - encourages alertness to clues in environment } \\
\text { and patient, to truly see rather than look inattentively }\end{array}$ & 57.3 & 58.9 & 59.4 & 59.7 & 52.8 & 57.4 & 0.389 & 0.249 \\
\hline Teacher & $\begin{array}{l}\text { Skilful and accurate in assessing and evaluating a learner - correctly judges a } \\
\text { learner's true proficiency, strengths and weakness }\end{array}$ & 56.7 & 56.7 & 54.1 & 56.8 & 57.3 & 58.9 & 0.887 & 0.464 \\
\hline Teacher & Well organised and possesses excellent time management skills (good planner) & 52.5 & 57.1 & 52.4 & 54.0 & 46.0 & 54.3 & 0.404 & 0.246 \\
\hline Teacher & Makes students feel empowered & 47.0 & 39.0 & 44.1 & 51.8 & 54.4 & 45.7 & $0.001^{*}$ & $0.001^{*}$ \\
\hline Teacher & Teaches professionalism & 41.9 & 47.6 & 44.1 & 48.2 & 32.7 & 39.5 & $0.001^{*}$ & $0.003^{*}$ \\
\hline Teacher & $\begin{array}{l}\text { Does not encourage student participation during theory lecture classes } \\
\text { (inversely phrased) }\end{array}$ & 32.8 & 24.7 & 32.9 & 32.4 & 36.3 & 41.1 & $0.005^{*}$ & $<0.001^{*}$ \\
\hline
\end{tabular}




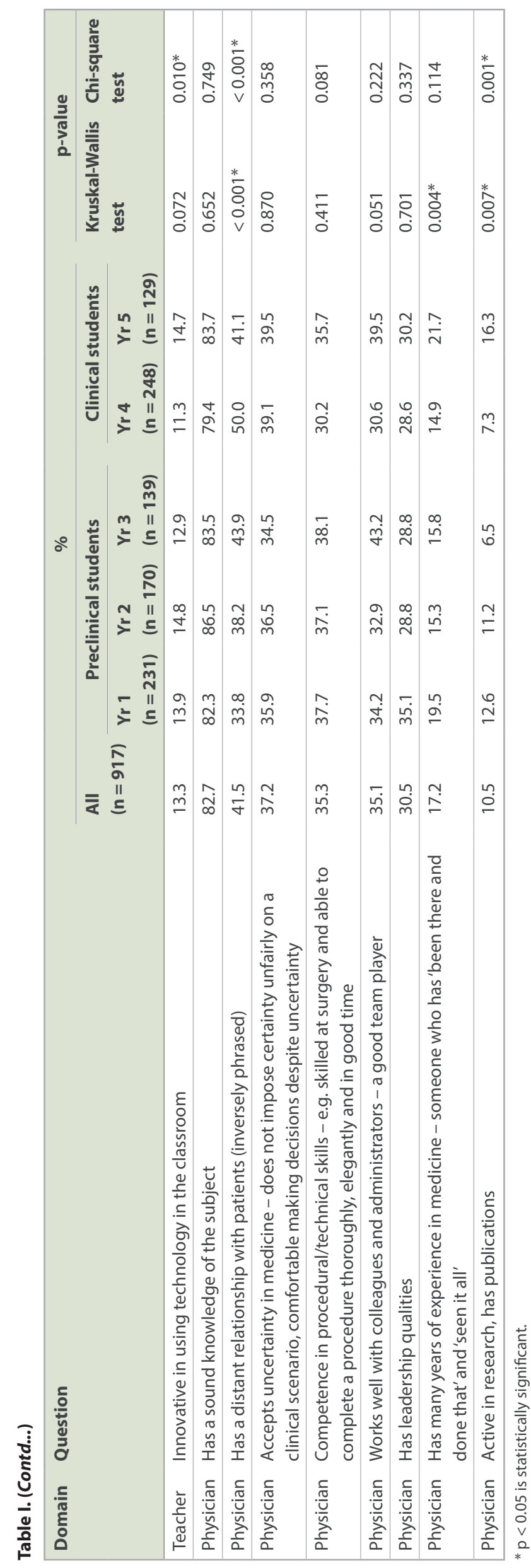

students' ( $p<0.001$ ); and 'makes students feel empowered' $(p=0.001)$. A higher proportion of students in the preclinical years rated 'being punctual' $(p=0.002)$ and 'teaches professionalism' $(p=0.003)$ more highly when compared to students in the clinical years (Table I). Based on the proportion of favourable Likert scale scores, the three least valued characteristics were also common across all five years of study: 'active in research, has publications' ( $10.5 \%$ of all respondents); 'innovative in using technology in the classroom' (13.3\%); and 'has many years of experience' (17.2\%).

The aggregate percentage of responses for each domain that was scored 5 on the Likert scale by students of each year indicated that characteristics in the human and teacher domains were consistently scored 5 by over $50 \%$ of students from Years 1-5 (Table III).

\section{DISCUSSION}

Since the top four characteristics were similar across all five years of medical students, they can be considered high-yield characteristics with transferable value across different teaching contexts, be it in a lecture room or a bedside teaching session. Some of the top characteristics found in this study, such as enthusiasm and communication skills, ${ }^{(13)}$ were also emphasised in the existing literature, including the non-medical teaching literature, ${ }^{(14-16)}$ suggesting greater generalisability.

A common theme in the clinical years was emphasising characteristics that facilitate interaction and involvement, such as approachability, constructive criticism and encouraging participation. We postulate that this may be related to increased personal interaction between teachers and learners during the clinical years, with the primacy of small-group bedside tutorials and involvement in daily ward work. For instance, approachability opens the door to interaction between the learner and teacher. This was consistent with an emphasis on constructivist teaching strategies in the later stages of medical training, which emphasise learner involvement in meaningful tasks in real-world contexts, cognitive apprenticeships and social negotiation through debate and discussion.

Although this was not statistically significantly different across the years, we note that communication skills were most often specifically selected as the most important characteristic by preclinical students. This may be a result of the predominance of didactic lectures in the preclinical years, where the effects of good or poor communication skills are amplified.

There was no overall difference across the years in the emphasis on human characteristics and teacher characteristics. In general, human and teacher characteristics were rated highly more commonly than physician characteristics. Human and teacher characteristics had almost equal weightage, with human characteristics being slightly more valued. This was different from reports from other Asian countries such as Japan, ${ }^{(5)}$ suggesting that Asian medical learners are not homogenous in their desired medical teacher characteristics and that the balance between characteristics is individualised according to each country's unique cultural context.

In stark contrast to the other physician characteristics, which tended to be poorly rated, having sound knowledge 
Table II. Characteristics selected by respondents as the single most important.

\begin{tabular}{|c|c|c|c|c|c|c|}
\hline Yr & First & No. (\%) & Second & No. (\%) & Third & No. (\%) \\
\hline 1 & Good communication skills & 46/231 (19.9) & $\begin{array}{l}\text { Provides clear } \\
\text { explanations }\end{array}$ & $24 / 231(10.4)$ & $\begin{array}{l}\text { Enthusiastic and has passion } \\
\text { to teach }\end{array}$ & 18/231 (7.8) \\
\hline 2 & Good communication skills & $25 / 170(14.7)$ & $\begin{array}{l}\text { Has a sound knowledge of } \\
\text { subject }\end{array}$ & $21 / 170(12.4)$ & Provides clear explanations & $20 / 170(11.8)$ \\
\hline 3 & Provides clear explanations & $20 / 139(14.4)$ & $\begin{array}{l}\text { Good communication } \\
\text { skills }\end{array}$ & $15 / 139(10.8)$ & $\begin{array}{l}\text { Enthusiastic and has passion } \\
\text { to teach }\end{array}$ & $12 / 139(8.6)$ \\
\hline 4 & $\begin{array}{l}\text { Enthusiastic and has } \\
\text { passion to teach }\end{array}$ & $34 / 248(13.7)$ & $\begin{array}{l}\text { Provides clear } \\
\text { explanations }\end{array}$ & $28 / 248(11.3)$ & Is easily approachable/affable & $25 / 248(10.1)$ \\
\hline 5 & Provides clear explanations & $22 / 129(17.1)$ & $\begin{array}{l}\text { Enthusiastic and has } \\
\text { passion to teach }\end{array}$ & $12 / 129(9.3)$ & Is easily approachable/affable & $9 / 129(7.0)$ \\
\hline
\end{tabular}

Table III. Aggregate percentage of responses for each domain that scored 5 on the Likert scale (or 1 if inversely phrased).

\begin{tabular}{|lcccccc|}
\hline \multirow{2}{*}{ Domain } & \multicolumn{6}{c}{ \% } \\
\cline { 2 - 5 } & All & \multicolumn{3}{c|}{ Preclinical students } & \multicolumn{2}{c|}{ Clinical students } \\
\cline { 3 - 4 } & & Yr 1 & Yr 2 & Yr 3 & Yr 4 & Yr 5 \\
\hline Human & 56.8 & 57.5 & 56.7 & 59.6 & 55.1 & 55.9 \\
\hline Teacher & 53.4 & 52.4 & 51.5 & 56.1 & 52.8 & 54.8 \\
\hline Physician & 36.3 & 36.4 & 35.8 & 36.8 & 35.0 & 38.5 \\
\hline
\end{tabular}

of the subject was a top four characteristic that was common across all four years. Of the top four characteristics, two were teacher characteristics, one was a human characteristic and one was a physician characteristic. If the other overall most popular characteristic of 'being patient with others' were included, then a total of two human characteristics, two teacher characteristics and one physician characteristic would be in the top five. Our interpretation of this finding was that medical teachers must have a good understanding of the subject, but beyond that, a broad base of teacher and human characteristics plays a greater role. This is consistent with the assertion by Irby ${ }^{(17)}$ that medical teachers do not necessarily need to be content experts and top-notch physicians but should instead have a balance of medical knowledge specifically relevant for education and various other domains of knowledge, including teaching skills and knowledge of learners. It is also consistent with our finding that medical students do not emphasise the importance of their medical teacher having many years of experience.

These results suggest focus areas for faculty development, selection and allocation. Given the presence of a core set of top characteristics that were common across all five years of medical students, development programmes for faculty who teach medical students may include training in these top characteristics as part of a core curriculum. Such training would be of high yield and transferable across different levels of medical students, and therefore represent good returns on training investment. Although it may seem difficult to change human characteristics, Schiffer et $\mathrm{al}^{(18)}$ argue that non-cognitive characteristics are both measurable and modifiable, allowing for growth. It would be useful to determine whether these top characteristics are also valued by postgraduate residents in Singapore, which would further increase their transferability and add impetus to include training to enhance such characteristics in faculty development programmes.

Faculty members may also benefit from programmes that focus on developing specific skills according to the level they would be teaching at. For example, faculty development programmes may emphasise characteristics that facilitate interaction and participation when teaching clinical-year medical students. Faculty members can be allocated to teach specific levels of medical students according to the specific strengths of each faculty member and how these match the desirable characteristics at different levels of medical student training.

Intelligent implementation of such changes to faculty development and selection should be driven by perceptual data and also supported by objective data demonstrating improved learner outcomes. The top characteristics identified in this study, as well as the variations between different levels of training, provide the focus areas for further research to obtain such data. Such research should objectively assess and compare learner outcomes when learners are taught by medical teachers that rate highly on these characteristics, versus those who rate lower.

There are several limitations to our study. This was a perceptual study that did not quantify the impact of teachers with these perceived desirable characteristics against actual learner outcomes. It was limited to the medical student population and did not extend to other medical learners such as junior residents. It was also a single-centre study, thereby potentially limiting its generalisability. Within NUS Medicine, we garnered responses from $45 \%-82 \%$ of each batch of medical students. A substantial proportion of students did not participate in our study and may hold different views regarding desirable teacher characteristics, which could have led to non-response bias.

The strengths of the study included the use of a validated questionnaire derived from a broad base of characteristics in the current literature, as well as a large sample size capturing a majority of students at Singapore's largest medical school. Singapore's interesting cultural mix also adds a unique perspective to the existing Asian literature.

In conclusion, the top characteristics in this study were consistent across all years of medical students. Characteristics emphasised in the clinical years facilitate active learner 
participation, consistent with a shift from cognitivist strategies to constructivist strategies as learners progress. These characteristics are a potential area for further research, to determine whether they are associated with better objective learner outcomes.

Beyond a sound knowledge of the subject, human and teacher characteristics predominated over physician characteristics in our study. Faculty members teaching medical students may not have to be especially accomplished physicians to be perceived as good medical teachers. This difference from other Asian countries in the balance between human, teacher and physician characteristics suggests that Asian medical learners are not homogenous and that it is more important to consider the unique cultural context of each site.

\section{ACKNOWLEDGEMENT}

The authors would like to thank the authors from Melaka Manipal Medical College, Melaka, Malaysia, for their kind permission to adapt their questionnaire for use in this study.

\section{SUPPLEMENTARY MATERIAL}

The Appendix is available online at https://doi.org/10.11622/ smedj.2019097.

\section{REFERENCES}

1. Harden RM, Crosby J. AMEE Guide No 20: The good teacher is more than a lecturer - the twelve roles of the teacher. Med Teach 2000; 22:334-47.

2. Sutkin G, Wagner E, Harris I, Schiffer R. What makes a good clinical teacher in medicine? A review of the literature. Acad Med 2008; 83:452-66.
3. Salili F, Hong YY, Chiu CY. Multiple Competencies and Self-regulated Learning: Implications for Multicultural Education. Greenwich, CT: Information Age Publishing, 2001.

4. Kernan WN, Lee MY, Stone SL, Freudigman KA, O'Connor PG. Effective teaching for preceptors of ambulatory care: a survey of medical students. Am J Med 2000; 108:499-502.

5. Kikukawa M, Nabeta $\mathrm{H}$, Ono $\mathrm{M}$, et al. The characteristics of a good clinical teacher as perceived by resident physicians in Japan: a qualitative study. BMC Med Educ 2013; 13:100.

6. Singh S, Pai DR, Sinha NK, et al. Qualities of an effective teacher: what do medical teachers think? BMC Med Educ 2013; 13:128.

7. Jonassen DH. Evaluating constructivistic learning. Educ Technol 1991; 31:28-33.

8. Ertmer PA, Newby TJ. Behaviorism, cognitivism, constructivism: comparing critical features from an instructional design perspective. Perf Improv Quart 1993; 6:50-72.

9. Anglin GJ. Instructional Technology: Past, Present, and Future. Englewood, CO: Libraries Unlimited Inc, 1991.

10. Kua EH, Voon F, Tan CH, Goh LG. What makes an effective medical teacher? Perceptions of medical students. Med Teach 2006; 28:738-41.

11. Singapore Department of Statistics. Population Trends 2016. Available at http://www.singstat.gov.sg/docs/default-source/default-document-library/ publications/publications_and_papers/population_and_population_structure/ population2016.pdf. Accessed February 27, 2018.

12. Best universities for medicine 2017. Available at: https://www. timeshighereducation.com. Accessed September 22, 2017.

13. Althouse LA, Stritter FT, Steiner BD. Attitudes and approaches of influential role models in clinical education. Adv Health Sci Educ Theory Pract 1999; 4:111-22.

14. Feldman KA. The perceived instructional effectiveness of college teachers as related to their personality and attitudinal characteristics: a review and synthesis. Res High Educ 1986; 24:139-213.

15. Young S, Shaw DG. Profiles of effective college and university teachers. J Higher Educ 1999; 70:670-86.

16. Yilmaz A. Quality problem in teaching profession: qualities teacher candidates feel to be required of teachers. Educ Res Rev 2011; 6:812-23.

17. Irby DM. What clinical teachers in medicine need to know. Acad Med 1994; 69:333-42.

18. Schiffer RB, Rao SM, Fogel BS. Neuropsychiatry: A Comprehensive Textbook. 2nd ed. Philadelphia: Lippincott Williams and Wilkins, 2003 


\section{APPENDIX}

\section{Study on Learner Perceptions of Qualities of Good Medical Teachers (Modified Questionnaire)}

\section{Part 1}

- $\quad$ Please circle preferred options where available

Year of study: Medical school year 1 / 2/3 / 4 / 5 / Graduated

\section{Part 2}

- $\quad$ For each of the following characteristics, please give a rating of 1-5,
- 5 - strongly agree that this is a characteristic of a good teacher
- 4 - agree that this is a characteristic of a good teacher
- 3 - neutral with regards to being a good teacher
- 2 - disagree that this is a characteristic of a good teacher
- 1 - strongly disagree that this is a characteristic of a good teacher

- Shade the appropriate circle for each row

- You may also add up to three other characteristics of your choice that you think are not covered in the options below and give it the appropriate rating

\begin{tabular}{|c|c|c|c|c|c|c|}
\hline & Teacher characteristics & 1 & 2 & 3 & 4 & 5 \\
\hline 1 & $\begin{array}{l}\text { Has good communication skills - conveys ideas and concerns clearly to patients, } \\
\text { relatives, colleagues and students, listens well }\end{array}$ & 0 & 0 & 0 & 0 & 0 \\
\hline 2 & Has good presentation skills - memorable, a pleasure to listen to or to watch & 0 & o & O & o & ○ \\
\hline 3 & Uses a good sense of humour in teaching sessions & 0 & 0 & 0 & 0 & o \\
\hline 4 & Innovative in using technology in the classroom & 0 & O & O & O & o \\
\hline 5 & Well organised and possesses excellent time management skills (good planner) & 0 & o & O & O & o \\
\hline 6 & Inflexible regarding maintaining classroom discipline & o & $\circ$ & o & o & ○ \\
\hline 7 & Aware of students' interests and needs & o & O & O & o & ○ \\
\hline 8 & Is easily approachable/affable & o & O & O & O & ○ \\
\hline 9 & Does not encourage student participation during theory lecture classes & o & O & O & O & ○ \\
\hline 10 & Works well with colleagues and administrators - a good team player & o & O & O & O & ○ \\
\hline 11 & Inspiring and motivational to students & o & O & o & O & ○ \\
\hline 12 & Very generous in assessing the performance of students during exams & o & o & o & o & o \\
\hline 13 & Offers constructive criticism to students & o & ○ & o & o & ○ \\
\hline 14 & Trusts and respects students & o & $\circ$ & o & o & $\circ$ \\
\hline 15 & Caring and shows empathy towards students & $\circ$ & o & o & o & ○ \\
\hline 16 & Has leadership qualities & o & $\circ$ & O & 0 & ○ \\
\hline 17 & Punctual & o & o & O & 0 & ○ \\
\hline 18 & Unbiased - such as in assessment of and interaction with students & o & O & O & o & ○ \\
\hline 19 & Has a sound knowledge of the subject & 0 & O & o & o & ○ \\
\hline 20 & Enthusiastic and has passion to teach, enjoys teaching & o & O & o & o & o \\
\hline 21 & Honest, moral and ethical & o & ○ & o & o & ○ \\
\hline 22 & Active in research, has publications & o & O & O & o & o \\
\hline 23 & Willing to learn and open to change (flexible) & o & o & o & o & o \\
\hline 24 & $\begin{array}{l}\text { Competence in procedural/technical skills - e.g. skilled at surgery and able to } \\
\text { complete a procedure thoroughly, elegantly and in good time }\end{array}$ & o & o & o & o & o \\
\hline 25 & Has a distant relationship with patients & 0 & O & o & O & o \\
\hline
\end{tabular}




\begin{tabular}{|c|c|c|c|c|c|c|}
\hline & Teacher characteristics & 1 & 2 & 3 & 4 & 5 \\
\hline 26 & $\begin{array}{l}\text { Has many years of experience in medicine - someone who has 'been there and } \\
\text { done that' and 'seen it all' }\end{array}$ & 0 & o & 0 & o & o \\
\hline 27 & $\begin{array}{l}\text { Accepts uncertainty in medicine - does not impose certainty unfairly on a clinical } \\
\text { scenario, comfortable making decisions despite uncertainty }\end{array}$ & $\circ$ & o & o & o & o \\
\hline 28 & $\begin{array}{l}\text { Provides effective explanations, answers and demonstrations - easily } \\
\text { remembered, crystallises concepts accurately and succinctly }\end{array}$ & 0 & o & o & o & o \\
\hline 29 & Stimulates trainees' thinking & $\circ$ & $\circ$ & $\circ$ & $\circ$ & o \\
\hline 30 & $\begin{array}{l}\text { Encourages trainees' active involvement in clinical work e.g. patient care, patient } \\
\text { procedures }\end{array}$ & $\circ$ & ० & ○ & ○ & o \\
\hline 31 & $\begin{array}{l}\text { Skilful and accurate in assessing and evaluating a learner - correctly judges a } \\
\text { learner's true proficiency, strengths and weakness }\end{array}$ & O & $\circ$ & ० & $\circ$ & o \\
\hline 32 & Teaches professionalism & 0 & o & o & o & o \\
\hline 33 & $\begin{array}{l}\text { Emphasises observational skills - e.g. encourages alertness to clues in } \\
\text { environment and patient, to truly see rather than look inattentively }\end{array}$ & 0 & ○ & o & ○ & o \\
\hline 34 & Acts as a role model, sets an example & o & o & o & o & o \\
\hline 35 & Appreciates culture and different cultural backgrounds & o & o & o & o & o \\
\hline 36 & Impatient with others & O & o & o & o & o \\
\hline 37 & Makes students feel empowered & O & o & o & o & o \\
\hline 38 & Others: & o & o & o & o & o \\
\hline 39 & Others: & O & o & 0 & O & o \\
\hline 40 & Others: & 0 & 0 & 0 & 0 & 0 \\
\hline
\end{tabular}

- Choose the five most important characteristics (from the above listed) and rank them in order (you may use numericals)

Most important:

Important, but less so:

Thank you for completing this survey! 